\title{
Epidemic Inflammation: Pondering Obesity
}

\author{
Carl Nathan
}

Department of Microbiology \& Immunology, Weill Cornell Medical College, New York, New York, United States of America

\begin{abstract}
Over the past two decades, inflammation has been recognized as a major driver in the pathogenesis of several common diseases, including atherosclerosis, diabetes, cancer, and asthma. Over the same period, there has been a steep rise in the incidence of obesity, a major risk factor for these disorders. Inflammation of adipose tissue is now recognized to accompany obesity and contribute to its sequelae. Thus, whereas obesity is primarily a disorder of energy balance, it may be helpful to consider it also as a form of epidemic inflammation that predisposes to other forms of epidemic inflammation. It is a fundamental biologic challenge to understand how a positive energy balance and inflammation are linked. This work reviews evidence that reactive oxygen and nitrogen intermediates (ROI and RNI) help drive chronic inflammation in the obese. This is proposed to be a maladaptive instance of our evolved dependence on ROI and RNI for both homeostatic signaling and host defense. ROI and RNI are well suited for these seemingly contradictory dual functions by their metabolic origin, high diffusibility in water and lipid, atomic specificity, and large number of molecular targets. When we eat so much and work so little that we repeatedly generate reactive compounds at levels normally reserved for emergencies, we treat our own cells like invading microbes.
\end{abstract}

Online address: http://www.molmed.org

doi: 10.2119/2008-00038.Nathan

\section{OBESITY AS AN INFLAMMATORY DISEASE}

Between 1980 and 2004-in the space of a generation-more than half of Americans (1) were among the billion people worldwide who had become overweight (body mass index [BMI] $25-29 \mathrm{~kg} / \mathrm{m}^{2}$ ) or obese (BMI $\geq 30$ ). Obesity is a potentially lethal inflammatory disorder whose pathogenesis we are at a loss to explain. Inflammation is lifepromoting when it fights infection and helps heal wounds, but life-threatening when it kills pancreatic islet cells in diabetes, thickens blood vessels in atherosclerosis, mutates DNA and spurs blood supply in cancers, or constricts airways in asthma. We've made progress in understanding these older forms of epidemic inflammation [for example, (2)], but we lack a conceptual framework to help us understand the pathogenesis of inflammation in obesity.

Recognition of the link between inflammation and obesity dates to 1993, when the inflammatory cytokine tumor necrosis factor (TNF)- $\alpha$ was shown to arise from adipose tissue in obese rodents and contribute to their insulin resistance (3). Insulin resistance is a state in which fat, muscle, and liver cells fail to respond normally to insulin, which can lead to increased glucose and fatty acids in the circulation. Ten years later, it emerged that adipose tissue is infiltrated by macrophages in obese children and adults (4) and mice (5), in proportion to how far they exceed normal body weight. These macrophages express TNF, inducible nitric oxide synthase (iNOS), and other inflammatory substances. Very recently, changes diagnostic of inflammation-increased leakiness of vessels and adhesion of leukocytes and platelets-were documented in the microcirculation of visceral, but not subcutaneous, adipose tissue in obese but not lean mice (6). The products arising from inflamed adipose tissue (adipositis) contribute to an in-
Address correspondence and reprint requests to Carl Nathan, Department of Microbiology \& Immunology, Weill Cornell Medical College, 1300 York Avenue, Box 62, New York, NY 10065, USA. Phone: 212-746-6505; Fax: 212-746-8587; E-mail: cnathan@med.cornell.edu. Submitted March 29, 2008; Accepted for publication April 8, 2008; Epub (www.molmed.org) ahead of print April 10, 2008. flammatory state in distant cells, such as endothelium, arterial and bronchial smooth muscle, and pancreatic islets. This systemic inflammation helps drives insulin resistance, endothelial dysfunction, and high blood pressure (hypertension), conditions that often progress to diabetes and atherosclerosis, and also predisposes to asthma and certain cancers (7).

It is not proposed that inflammation is an initial cause of obesity. Obesity results from chronic positive energy balance. However, obesity frequently leads to inflammation that appears to arise first in certain deposits of fat. Adipositis can exacerbate obesity by dysregulating adipocyte-derived regulators of feeding. In some obese individuals, cytokines arising from cells in fat appear to induce inflammation in distant sites, contributing substantially to obesity's adverse effects. I argue below that excess ROI and RNI appear to act as both products and mediators of adipositis and the wider inflammation that sometimes ensues. With excess ROI and RNI helping to drive vicious cycles, inflammation can be both an effect of obesity and a contributor to its progression and sequelae.

The recent upswing in the incidence of obesity suggests a key role of 
environmental factors. Attention has focused on microbes and nutrients. Let us consider them in turn.

\section{BLAME MICROBES}

When an inflammatory disease spreads like an epidemic, it must be scrutinized for an infectious cause, even if it appears to spread more readily via social than spatial links (8). There are provocative links between microbes and obesity. Germ-free mice are resistant to diet-induced obesity (9), raising the possibility that a specific microbe may cause adipositis. The putative pathogen might infect adipose tissue, as can Mycobacterium tuberculosis (10), or might infect adipocytes themselves, as can be seen in vitro with adenovirus 36 (10). The proportion of obese Americans far exceeds the proportion infected with M. tuberculosis, however, and there is no evidence that an adenovirus localizes in adipose tissue in vivo and inflames it. Alternatively, a microbe might release a product that localizes to fat, much as streptococcal cell walls can localize in joints and cause arthritis. Yet another way to account for the dependence of dietinduced obesity on resident microbes is that the innate immune system does not develop normally in a germ-free host. Thus, without the resident microbiota, the inflammatory response to a nonmicrobial stimulus may be dampened. Mice are also relatively resistant to diet-induced obesity when the gut microbiota are present but components of the host's microbial sensing machinery, such as CD14 or TLR4, are missing or faulty $(11,12)$. Finally, the microbiota, particularly colonic Firmicutes, mobilize more calories from food than the host does on its own (13); however, one would expect a compensatory regulation of appetite. In short, although we should not abandon the idea that obesity could have an infectious cause, it would be more prudent to consider that the problem is of our own making.

\section{BLAME FOOD}

Obesity might instead be caused by defects in the signaling systems that tell us when to eat and when to stop.
Hormones from the gut, brain, skeletal system, and fat regulate these powerful urges, and such hormonal circuits are dysregulated in the obese. However, obesity is only rarely attributable to mutations in genes encoding such a hormone or its receptor. Variants in a putative nucleic acid demethylase (14) predispose to obesity (15). Variants in any number of other genes may eventually be found to do so as well. Nonetheless, genetic effects alone could not account for a doubling in the incidence of obesity in one generation. This rate of change mandates a focus on the environment.

Two environmental factors that we internalize, glucose and fat, are good candidates. These or their products might directly engage cell-surface receptors and trigger pro-inflammatory signals. For example, excess ingestion or production of glucose might increase the levels of advanced glycation endproducts (AGEs), which engage their receptor (RAGE) on macrophages and other cells that can induce oxidant stress and activate NF- $\mathrm{KB}$, a pro-inflammatory transcription factor (16). Fatty acids can bind cellular proteins that are homologous to $G$ protein-coupled receptors (17), but the binding is blocked at physiologic concentrations of albumin and $\mathrm{Ca}^{2+}$. Likewise, oleate and palmitate (bound to albumin) can activate inflammatory cells by binding to the CD14/ TLR4/MD2 receptor complex, in which MD2 physiologically binds bacterial endotoxic lipopolysaccharide and other microbial products (18). The ultra-lowaffinity interaction of fatty acids with CD14/TLR4/MD2 seems unlikely to account for obesity-associated inflammation, however, because it has been demonstrated in vitro at levels of free fatty acids that circulate normally in plasma.

If activation of inflammatory signaling cascades by plasma membrane receptors for glucose, glucose-derived products, or fatty acids is unlikely to be the whole story, we should direct our attention to the cytosol. Hyperglycemia does not promote atherosclerosis in mildly hyperlipidemic mice unless they express aldose reductase, a cytosolic, glucose-metabolizing enzyme (19). Moreover, adipositis and insulin resistance caused by feeding mice a high-fat diet require macrophage expression of cbl-associated protein, a cytosolic protein required for glucose transporters to move to the plasma membrane in response to insulin (20). Finally, an anti-inflammatory fatty acid binding protein called aP2 (21) is cytosolic. These findings suggest that the key actions of high glucose and high fat depend on metabolism in the cytosol.

\section{CYTOSOLIC CANDIDATES: ROI AND RNI}

What cytosolic signals are generated in common by metabolism and inflammation that might regulate both? Evidence favors two answers: ROI and RNI. These sets of compounds appear to be generated by organisms in every phylogenetic class throughout the aerobic biome. ROI and RNI regulate intracellular signaling and gene expression differently depending on whether they are produced at low levels for brief periods or high levels for prolonged periods, as occurs during inflammation (22). High levels of these mediators also promote mutagenesis, cytostasis, apoptosis, and necrosis (23-26).

It is widely appreciated that high levels of ROI and RNI are generated during inflammatory and immune responses and play a critical role in host defense (27). Less obvious but equally fundamental are their low-level generation by, and impact on, intermediary metabolism. A major function of intermediary metabolism is the generation and disposition of electrons that accumulate temporarily in NADPH and NADH, and the closely associated response to and regulation of the intracellular concentration of $\mathrm{O}_{2}$. $\mathrm{O}_{2}$ and NADPH or NADH are cosubstrates for generation of ROI, depending on the source, whereas $\mathrm{O}_{2}$ and NADPH are cosubstrates for generation of RNI. ROI and RNI in turn regulate intermediary metabolism in multiple ways. For example, a major physiologic role of nitric oxide (NO) is to regulate the rate of mitochondrial respiration (28), and $\mathrm{H}_{2} \mathrm{O}_{2}$ rapidly and stoichiometrically decarboxylates $\alpha$-ketoacids, such as pyruvate, 
$\alpha$-ketoglutarate, and oxaloacetate (29). In mice infected with Staphylococcus aureus, products of iNOS inactivate the pathogens' pyruvate dehydrogenase and pyruvate formate lyase, forcing the bacteria to dispose of excess reducing equivalents by secreting lactate (30). If the iNOS in adipocytes similarly inhibits their pyruvate dehydrogenase, it might help drive their deposition of excess reducing equivalents in the synthesis and storage of fatty acids. ROI and RNI also regulate each other's generation. For example, NO promotes mitochondrial generation of superoxide $\left(\mathrm{O}_{2}^{-}\right)(28) \cdot \mathrm{O}_{2}^{-}$ titrates $\mathrm{NO}$, leading to formation of a much more reactive form of RNI, peroxynitrite $\left(\mathrm{OONO}^{-}\right)$.

There is striking evidence for increased production of RNI, probably $\mathrm{OONO}^{-}$, in people experiencing hyperglycemia. This is the simplest way to explain the close coupling between the level of glucose in their blood and the level of methyl nitrate in their breath (31). In mice fed a high-fat diet, pharmacologic blockade of NO synthesis improves insulin sensitivity and reduces weight (32).

There is copious evidence for production of excess ROI by adipocytes, endothelial cells, and vascular smooth muscle cells exposed to high glucose in vitro or in vivo (33-35). Moreover, the inflammatory changes (such as NF- $\mathrm{KB}$ activation and formation of AGEs) and insulin resistance associated with high glucose levels are suppressed by antioxidant treatment of adipocytes or mice $(34,35)$.

When glucose is elevated, excess ROI arise from three prominent sources: mitochondria $(36,37)$, the endoplasmic reticulum (ER) (38), and a family of NADPH oxidases (NOXs). Mice are protected from diet-induced obesity by partial inhibition of mitochondrial electron transport, the source of mitochondrial ROI (39). They are similarly protected by compounds that reduce ER stress, a process that provokes excess ROI generation by the ER (38). Finally, NOXs are selectively elevated in white adipose tissue of obese mice and generate ROI upon exposure of adipocytes to fatty acids. Treatment of

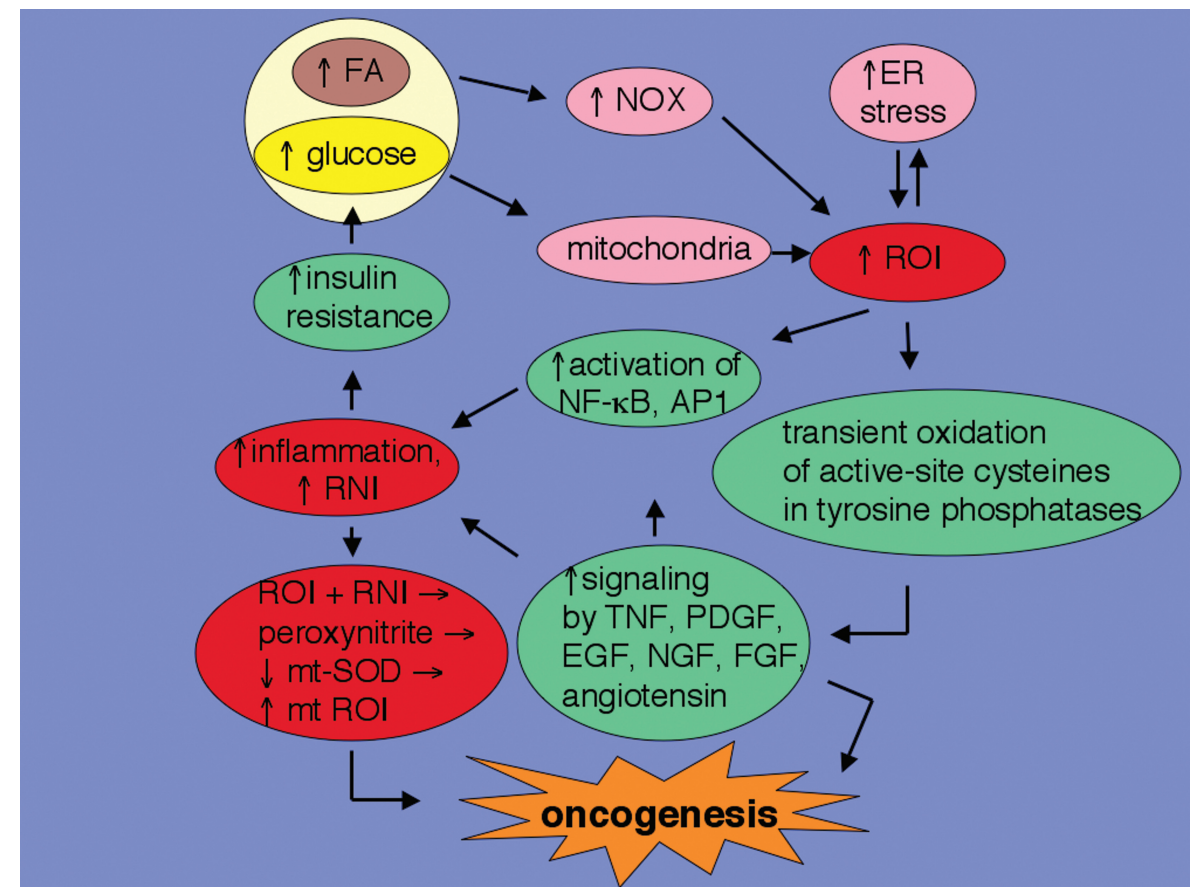

Figure 1. Vicious cycle at the molecular level, set in motion by excess consumption of glucose and fat. SOD, superoxide dismutase; $\mathrm{mt}$, mitochondrial.

these mice with NOX inhibitors improves their diabetes and hyperlipidemia (40).

\section{VICIOUS CYCLES}

A striking feature of metabolismtriggered ROI and RNI generation is the profusion of feed-forward loops that amplify their production. For example, glucose-triggered ROI drive cells to produce a lipid aldehyde, 4-OH-trans-2nonenol (HNE) (41), which reacts with glutathione. Aldose reductase reduces glutathionyl-HNE to glutathionyldihydroxynonene, which induces TNF, interleukin (IL)-1 $\beta$, IL-6, and chemokines (41). The chemokines can attract and activate macrophages to produce more ROI and RNI. ROI and RNI can damage DNA, leading to activation of NF- $\mathrm{B}$, which in turn enhances their cellular production (42). In addition, high glucose synergizes with cytokines to induce iNOS in vascular smooth muscle cells (43). The resulting RNI can inhibit mitochondrial electron transport, promoting ROI production $(28,44)$. The $\mathrm{OONO}^{-}$ formed as a result inhibits mitochondrial superoxide dismutase, allowing more $\mathrm{OONO}^{-}$to be formed, inhibiting mitochondrial electron transport at additional steps and generating more ROI. Figure 1 summarizes some of these molecular events.

The impact of these amplification loops on endothelial NOS helps explain the vascular dysfunction that underlies many of obesity's harmful effects. Mitochondrial ROI generation triggered by exposing endothelial cells to high glucose promotes glycosylation of a site on endothelial nitric oxide synthase (eNOS) that normally undergoes phosphorylation when the kinase Akt activates the enzyme (45). As a result, eNOS becomes harder to turn on. Normally, eNOS functions to relax underlying vascular smooth muscle and to prevent overlying platelets and white blood cells from adhering. Thus, dysfunction of eNOS may help account for the tendency of people who repeatedly metabolize excess glucose to develop high blood pressure and to allow platelets and monocytes to adhere in their vasculature. The latter 
events are key steps in the development of atherosclerosis and its complications, such as myocardial infarction. Similarly, the $\mathrm{OONO}^{-}$that arises when glucose is elevated suppresses GTP cyclohydrolase, the rate-limiting enzyme in formation of tetrahydrobiopterin, a NOS cofactor (46). Without tetrahydrobiopterin, eNOS makes superoxide instead of vasoprotective levels of $\mathrm{NO}$ (47). If cells generate even higher levels of $\mathrm{OONO}^{-}$, they oxidatively inactivate the remaining tetrahydrobiopterin (48), thus contributing to vascular dysfunction.

Some of the evidence discussed above is based on glucose being elevated in cell culture or blood. Most obese people do not have elevated blood glucose, however, and many with diabetes or prediabetes, despite sometimes having elevated blood glucose, are not obese. Nonetheless, the propensity of obese people to become diabetic may hold important clues to the pathophysiology that drives the progression from adipositis to systemic inflammation. In those who are overweight or obese but not yet diabetic or prediabetic (meaning that their blood glucose does not exceed a defined level when fasting or after a standardized meal), repetitive consumption of much food is likely to lead to excessive ROI and RNI production in adipocytes and endothelial cells. Food ingestion sufficient to promote excessive formation of cellular ROI and RNI may not be reflected in abnormal blood glucose levels. Overeating may lead to excess metabolic throughput without an elevation of blood glucose, or there may be elevations that do not exceed what has been defined as the upper limit of normal. Finally, overly frequent eating may disrupt diurnal rhythms important for metabolic control (49).

Metabolism, like inflammation, has complex control mechanisms that can fail. Among the most important metabolic regulators are nuclear receptors, and these also control inflammation (50). Moreover, nuclear receptors can both affect and be affected by ROI and RNI. For example, the metabolism-regulating nuclear recep- tor Rev-erb $\alpha$ includes a heme group, which is likely to be subject to redox regulation and nitrosylation (49). RNI nitrosate fatty acids and nitro-fatty acids can activate another nuclear receptor, peroxisome proliferator-activated receptor- $\gamma$ (PPAR $\gamma)$ (51), that suppresses hyperglycemia and inflammation (52). Although this is a potentially anti-inflammatory action of RNI, it raises the possibility that some of the numerous pro-inflammatory actions of RNI may involve dysregulation of nuclear receptor signaling.

\section{A FUNDAMENTAL LINK BETWEEN HOMEOSTATIC SIGNALING, INFLAMMATION, AND HOST DEFENSE}

There is an enormous literature on intracellular signaling by ROI and RNI. Yet, many if not most, published cell signaling models omit them. This may reflect disbelief that the same molecules can both signal and kill, doubt that seemingly nonspecific molecules can regulate cell function, and confusion over their contrasting effects in different settings.

In fact, it is commonplace in biology for organisms to compete by interfering with each other's signaling, and evolution appears to favor signaling molecules as both mediators and targets of cytotoxicity (26). Thus the function of ROI and RNI in killing microbes does not exclude, but rather predicts, that they also serve as important signaling molecules. The distinction between the two functions depends on timing and amount. Insulin signaling offers a classic example. The small amounts of $\mathrm{H}_{2} \mathrm{O}_{2}$ produced in cells on binding insulin are required to optimize phosphorylation of downstream signaling molecules by transiently inactivating tyrosine phosphatases through reversible oxidation of their active-site cysteines. In contrast, in large amounts or on prolonged exposure, $\mathrm{H}_{2} \mathrm{O}_{2}$ inhibits insulin signaling.

ROI and RNI also display exquisite specificity, although this specificity is atomic rather than molecular (26). Whereas ROI and RNI react with only a few kinds of atoms in particular states, such as acidic sulfurs in the side chains of active-site cysteine residues, such atoms are present in many different molecules, including the active sites of most phosphatases, as mentioned above.

When a cell responds to a signal, it commits resources. Facing multiple and successive signals, the cell must balance its commitments with its resources. The diffusible nature and atomic specificity of ROI and RNI allows them to integrate many signals and tune numerous signaling pathways in accord with the cell's metabolic state. Thus, RNI and ROI help link the behavior of a cell to its metabolic budget.

\section{ADIPOCYTE-SPECIFIC VULNERABILITIES AND CONSEQUENCES}

The foregoing discussion cited experiments with adipocytes, vascular smooth muscle cells, and endothelial cells. If excess caloric consumption triggers excess production of ROI and RNI in many different kinds of cells, why is adipositis the earliest histologic evidence of obesityassociated inflammation?

Adipocytes are unique among mammalian cells in that the vast majority of the cells' volume is occupied by fat. Oxygen dissolves to a far higher concentration in lipids than in water. The oxygen concentration in the water phase was found to be lower in adipocytes in obese mice than in nonobese mice, in part because adipocytes increase in size with obesity (hypertrophy) and this interferes with their blood supply $(53,54)$, as do the adherent leukocytes and platelets in their microcirculation (6). Paradoxically, abnormally low levels of oxygen in cell water (hypoxia) increase mitochondrial generation of ROI (55). Thus, oxygendeprived adipocytes may produce ROI in part because they are hypoxic, and this production may be more sustained than in other kinds of hypoxic cells because the mitochondria of adipocytes abut a lipid-based depot of $\mathrm{O}_{2}$.

At the same time, the fat vacuole may put adipocytes at high risk for formation of lipid oxidation products, which can trigger cell death (56). Perhaps for this reason, an increased proportion of 
adipocytes in obese individuals are necrotic (57). Hypertrophic adipocytes are surrounded by activated macrophages. Activated macrophages respond to necrotic cell debris by generating oxidants and chemokines. Chemokines in turn promote further macrophage infiltration and activation (58). For all these reasons, adipocytes in obese individuals may be exposed to a greater oxidant load than most other cells.

Excess levels of ROI and RNI can also result from their reduced consumption. The antioxidant capacity of adipocytes is likely to be severely restricted because their cytosol is scant. Whatever their starting levels, some of the antioxidant reserves of adipocytes decline in obesity. Indeed, levels of superoxide dismutase, glutathione peroxidase, and catalase are markedly lower in adipocytes from obese mice than from nonobese mice (40).

Taken together, the foregoing considerations prompt the testable prediction that hypertrophic adipocytes may have the lowest antioxidant capacity of any cells relative to their oxidant load.

Adipose tissue normally secretes appetite-regulating hormones (adipokines). Obesity is not only associated with increased ROI generation selectively in white adipose tissue, but also with dysregulation of adipokine production. It is particularly significant that this defect is correctable in mice with compounds that inhibit ROI-generating NOXs (40). Thus, ROI-dependent damage to adipocytes may contribute to loss of appetite control. This may make it exceptionally difficult to reverse preexisting obesity through diet alone. In effect, adipositis sustains a feed-forward loop in both figurative and literal senses. Figure 2 schematizes vicious cycles that may operate at the interorgan level.

\section{EVOLUTIONARY IMPLICATIONS}

Malnutrition (in the original sense of undernutrition) dysregulates inflammation and suppresses immunity. It is now emerging that overnutrition does the same. The adverse impact of obesity on immunity is

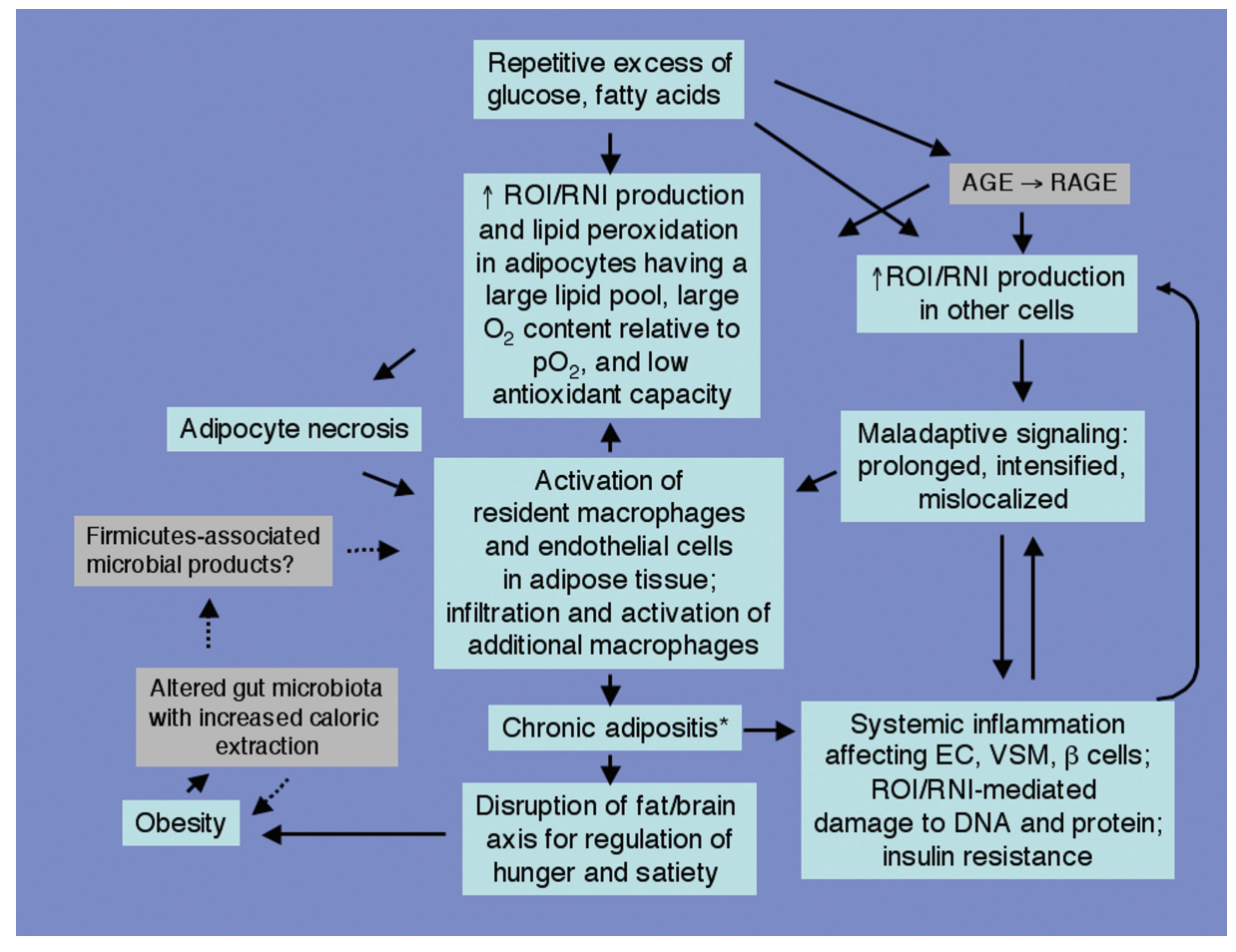

Figure 2. Vicious cycles at the organ level, set in motion by excess consumption of glucose and fat. EC, endothelial cells; VSM, vascular smooth muscle; $\beta$ cells, insulin-producing cells in the pancreas. Asterisk with chronic adipositis: leading to altered production of leptin, adiponectin, resistin, visfatin, apelin, vaspin, macrophage chemotactic protein 1, TNF, etc. Dashed lines indicate the most speculative interactions.

particularly striking in tuberculosis, a disease that may have shaped recent human evolution. In the pre-antibiotic era, it was observed that type 1 diabetes predisposes to tuberculosis. It is now becoming clear that obesity-associated prediabetes and type 2 diabetes increase the contagiousness of tuberculosis and prolong posttreatment infectiousness (59-61). Suppressed ability to generate interferon (IFN)- $\gamma$ may contribute to the increased susceptibility (62), as IFN- $\gamma$ enhances the antimicrobial capacity of macrophages (63) and deficiency in its production or signaling underlies most syndromes of Mendelian susceptibility to mycobacterial infection (64). In India, the case burden of tuberculosis attributable to obesity and/ or diabetes has been estimated to markedly exceed that attributable to infection by HIV $(59,60)$. Thus, until recently, tuberculosis may have culled the obese and their closest contacts (their offspring), restricting the prevalence and heritability of obesity. In the pre-antibiotic era, tuberculosis was called "consumption." Today's obesity epidemic may reflect the intersection of reduced "consumption" with excess consumption.

\section{THERAPEUTIC IMPLICATIONS}

With an increased incidence of diabetes, hypertension, atherosclerosis, asthma, cancer, and tuberculosis, we do not want for reasons to halt and reverse the obesity epidemic. Without question, prevention is the best strategy, and this will presumably require increased education and increased opportunity for altered diet and exercise. Nonetheless, with over half the population in some countries already overweight or obese, therapeutic intervention is indispensable. What will work besides surgery?

Of course, the primary therapy should be directed to restoring energy balance. The present analysis leads to 
two predictions. Insofar as people strive to reduce pre-existing obesity by eating less, we should anticipate that behaviorbased therapies are unlikely to be widely effective until adipositis is controlled. Second, medical control of adipositis will probably require combination therapy. Many pharmaceutical firms are trying to correct dysregulation of hormones that control appetite and to block inflammatory mediators. Two innovative but potentially risky experimental approaches aim to reduce ROI generation by the ER (38) or by mitochondria (39). Such interventions raise concerns about how the host would handle stress. Moreover, there are three major sources of the excess ROI in obesity-mitochondria, ER, and NOXs. Suppressing ROI generation by either mitochondria or ER leaves the other two sources of excess ROI unopposed, and their output might even undergo a compensatory increase. It might be safer and more efficient if one arm of combination therapy instead aims to enhance cellular antioxidant capacity in adipocytes, endothelium, vascular smooth muscle cells, and pancreatic islets. For example, Nrf is a master transcriptional regulator of diverse antioxidant pathways, including heme oxygenase 1 , thioredoxin, thioredoxin reductase, some peroxiredoxins, $\gamma$-glutamylcysteine synthetase, glutathione-S-transferases, glutathione peroxidase, glutathione reductase, superoxide dismutase, and $\mathrm{NAD}(\mathrm{P}) \mathrm{H}$ quinone oxidoreductase (65). Nrf activators have been used successfully in experimental animals to reduce the incidence of cancer (66).

\section{SUMMARY: EPIDEMIC OBESITY FROM THE PERSPECTIVE OF HOST-MICROBE INTERACTIONS}

Obesity is the newest epidemic inflammatory disease and the only one that feeds the growth of most of the others. Several experimental questions and hypotheses about obesity arise from thinking about the disease in terms of inflammation's evolved role in host defense (see Sidebar).

\section{Experimental Challenges}

- What amounts of ingested glucose or glucose-generating foods, and what amounts of fat, lead to generation of increased amounts of ROI and RNI in adipocytes and endothelial cells in situ in human subjects? How do these amounts relate to the glucose load used to test "glucose tolerance"? Which tests scale best with body mass index? Which tests best correlate with indices of inflammation, insulin resistance, endothelial dysfunction, hypertension, and atherosclerosis?

- What is the ratio of oxidant load to anti-oxidant capacity in adipocytes? Does the ratio scale with body mass index? Does it exceed the ratio in other cells?

- Is control of appetite restored in obese subjects when ROI- and RNIdependent damage to adipocytes is prevented?

- Among medical interventions, can ROI- and RNI-dependent cell dysfunction in obesity best be prevented by modulating appetite, inflammatory mediators, ROI and RNI production, or antioxidant capacity? Or by combinations of these?

At the population level, epidemic obesity may be rising because markedly increased consumption and markedly decreased exercise have coincided with a decreased incidence of tuberculosis, and perhaps of other potentially fatal infectious diseases to which obesity may predispose. However, as A. Casadeval has pointed out (personal communication), the abrupt upswing in the incidence of obesity after 1980 suggests the influence of additional contributory factors. Further research should explore a possible relation to the growing use of antibiotics (67), growth-promoting hormones (68), and other pharmaceuticals in the human food chain and water supply (69) over the same period.

At the tissue level, inflammatory obesity may originate in adipose tissue because that tissue has both a unique propensity for and vulnerability to oxidant injury. Both of these traits become more extreme as adipocytes enlarge. Adipositis becomes problematic because biochemical and hormonal feed-forward mechanisms perpetuate and exacerbate it, until inflammation becomes systemic.

At the molecular level, obesity may arise because repetitive overproduction of NADPH and NADH in hypoxic cytoplasm adjacent to an $\mathrm{O}_{2}$-rich lipid vacuole leads to excessive, sustained production of ROI and RNI. Their increased production mimics, to a degree, an evolved system of host defense designed to disrupt signaling in pathogens. At lower fluxes, ROI and RNI serve to integrate signaling in the host because their levels are controlled by metabolism, they are diffusible in water and lipid, their specificity is atomic, and their range of molecular targets is wide. It is for these same reasons that higher levels of ROI and RNI poison microbes. Although the same properties account for the ability of high-level ROI and RNI production to damage host cells, this is normally a brief and tolerable side effect of defense in a multicellular host that is prepared to sacrifice some of its own cells and tissues to protect the organism. Despite the risks and costs, the host's ability to produce ROI and RNI at high levels for antimicrobial defense offers a net evolutionary advantage, because it is impossible for a pathogen to evolve resistance to these compounds by loss of atomic targets.

At the philosophical level, our inflammatory and immune systems face challenges that change faster than we evolve. Inflammation in obesity is but one of many examples of the imperfection of inflammation as a tool of host defense. We can attribute this particular shortcoming to an environment recently created by 
human behavior that is radically different from that in which inflammatory responses evolved. When we eat so much and work so little that we repeatedly generate reactive compounds at levels normally reserved for emergencies, we treat our own cells like invading microbes. An infectious cause of epidemic obesity may exist, but it need not be postulated, because we have found a way to mimic one.

\section{ACKNOWLEDGMENTS}

Comments by Kyu Rhee (Weill Cornell Medical College) and Arturo Casadeval (Albert Einstein College of Medicine) and editorial suggestions by Heather van Epps (Journal of Experimental Medicine) are greatly appreciated. The Department of Microbiology \& Immunology is supported by the William Randolph Hearst Foundation.

\section{REFERENCES}

1. Ogden CL, Carroll MD, Curtin LR, McDowell MA, Tabak CJ, Flegal KM. (2006) Prevalence of overweight and obesity in the United States, 1999-2004. JAMA 295:1549-55.

2. Nathan C. (2002) Points of control in inflammation. Nature 420:846-52.

3. Hotamisligil GS, Shargill NS, Spiegelman BM. (1993) Adipose expression of tumor necrosis factor-alpha: direct role in obesity-linked insulin resistance. Science 259:87-91.

4. Weisberg SP, McCann D, Desai M, Rosenbaum M, Leibel RL, Ferrante AW Jr. (2003) Obesity is associated with macrophage accumulation in adipose tissue. J. Clin. Invest. 112:1796-808.

5. Xu H, et al. (2003) Chronic inflammation in fat plays a crucial role in the development of obesity-related insulin resistance. J. Clin. Invest. 112:1821-30.

6. Nishimura $S$, et al. (2008) In vivo imaging in mice reveals local cell dynamics and inflammation in obese adipose tissue. J. Clin. Invest. 118:710-21.

7. Calle EE, Kaaks R. (2004) Overweight, obesity and cancer: epidemiological evidence and proposed mechanisms. Nat. Rev. Cancer 4:579-91.

8. Christakis NA, Fowler JH. (2007) The spread of obesity in a large social network over 32 years. N. Engl. J. Med. 357:370-9.

9. Backhed F, Manchester JK, Semenkovich CF, Gordon JI. (2007) Mechanisms underlying the resistance to diet-induced obesity in germ-free mice. Proc. Natl. Acad. Sci. U. S. A. 104:979-84.

10. Desruisseaux MS, Nagajyothi, Trujillo ME, Tanowitz HB, Scherer PE. (2007) Adipocyte, adipose tissue, and infectious disease. Infect. Immun. 75:1066-78.

11. Cani PD, et al. (2007) Metabolic endotoxemia initiates obesity and insulin resistance. Diabetes 56:1761-72.

12. Suganami T, Mieda T, Itoh M, Shimoda $Y$, Kamei $Y$, Ogawa Y. (2007) Attenuation of obesity-induced adipose tissue inflammation in $\mathrm{C} 3 \mathrm{H} / \mathrm{HeJ}$ mice carrying a Toll-like receptor 4 mutation. Biochem. Biophys. Res. Commun. 354:45-9.

13. Turnbaugh PJ, Ley RE, Mahowald MA, Magrini V, Mardis ER, Gordon JI. (2006) An obesity-associated gut microbiome with increased capacity for energy harvest. Nature 444:1027-31.

14. Gerken T, et al. (2007) The obesity-associated FTO gene encodes a 2-oxoglutarate-dependent nucleic acid demethylase. Science 318:1469-72.

15. Frayling TM, et al. (2007) A common variant in the FTO gene is associated with body mass index and predisposes to childhood and adult obesity. Science 316:889-94.

16. Yan SD, et al. (1994) Enhanced cellular oxidant stress by the interaction of advanced glycation end products with their receptors/binding proteins. J. Biol. Chem. 269:9889-97.

17. Itoh $Y$, et al. (2003) Free fatty acids regulate insulin secretion from pancreatic beta cells through GPR40. Nature 422:173-6.

18. Shi H, Kokoeva MV, Inouye K, Tzameli I, Yin H, Flier JS. (2006) TLR4 links innate immunity and fatty acid-induced insulin resistance. J. Clin. Invest. 116:3015-25.

19. Vikramadithyan RK, et al. (2005) Human aldose reductase expression accelerates diabetic atherosclerosis in transgenic mice. J. Clin. Invest. 115: 2434-43.

20. Lesniewski LA, et al. (2007) Bone marrow-specific Cap gene deletion protects against high-fat dietinduced insulin resistance. Nat. Med. 13:455-62.

21. Furuhashi M, et al. (2007) Treatment of diabetes and atherosclerosis by inhibiting fatty-acidbinding protein aP2. Nature 447:959-65.

22. Ehrt $S$, et al. (2001) Reprogramming of the macrophage transcriptome in response to interferon-gamma and Mycobacterium tuberculosis: signaling roles of nitric oxide synthase-2 and phagocyte oxidase. J. Exp. Med. 194:1123-40.

23. Nathan C. (1992) Nitric oxide as a secretory product of mammalian cells. FASEB J. 6:3051-64.

24. Sundaresan M, Yu ZX, Ferrans VJ, Irani K, Finkel T. (1995) Requirement for generation of $\mathrm{H}_{2} \mathrm{O}_{2}$ for platelet-derived growth factor signal transduction. Science 270:296-9.

25. Stamler JS, Lamas S, Fang FC. (2001) Nitrosylation: the prototypic redox-based signaling mechanism. Cell 106:675-83.

26. Nathan C. (2003) Specificity of a third kind: reactive oxygen and nitrogen intermediates in cell signaling. J. Clin. Invest. 111:769-78.

27. Nathan C, Shiloh MU. (2000) Reactive oxygen and nitrogen intermediates in the relationship between mammalian hosts and microbial pathogens. Proc. Natl. Acad. Sci. U. S. A. 97:8841-8.

28. Erusalimsky JD, Moncada S. (2007) Nitric oxide and mitochondrial signaling: from physiology to pathophysiology. Arterioscler. Thromb. Vasc. Biol. 27:2524-31.
29. O'Donnell-Tormey J, Nathan CF, Lanks K, DeBoer CJ, de la Harpe J. (1987) Secretion of pyruvate: an antioxidant defense of mammalian cells. J. Exp. Med. 165:500-14.

30. Richardson AR, Libby SJ, Fang FC. (2008) A nitric oxide-inducible lactate dehydrogenase enables Staphylococcus aureus to resist innate immunity. Science 319:1672-6.

31. Novak BJ, et al. (2007) Exhaled methyl nitrate as a noninvasive marker of hyperglycemia in type 1 diabetes. Proc. Natl. Acad. Sci. U. S. A. 104:15613-8.

32. Tsuchiya K, et al. (2007) Chronic blockade of nitric oxide synthesis reduces adiposity and improves insulin resistance in high fat-induced obese mice. Endocrinology 148:4548-56.

33. Brownlee M. (2001) Biochemistry and molecular cell biology of diabetic complications. Nature 414: 813-20.

34. Lin Y, et al. (2005) The hyperglycemia-induced inflammatory response in adipocytes: the role of reactive oxygen species. J. Biol. Chem. 280: 4617-26.

35. Houstis N, Rosen ED, Lander ES. (2006) Reactive oxygen species have a causal role in multiple forms of insulin resistance. Nature 440:944-948.

36. Nishikawa T, et al. (2000) Normalizing mitochondrial superoxide production blocks three pathways of hyperglycaemic damage. Nature 404 787-90.

37. Quijano C, Castro L, Peluffo G, Valez V, Radi R. (2007) Enhanced mitochondrial superoxide in hyperglycemic endothelial cells: direct measurements and formation of hydrogen peroxide and peroxynitrite. Am. J. Physiol. Heart Circ. Physiol. 293:H3404-14.

38. Ozcan U, et al. (2006) Chemical chaperones reduce ER stress and restore glucose homeostasis in a mouse model of type 2 diabetes. Science 313: 1137-40.

39. Pospisilik JA, et al. (2007) Targeted deletion of AIF decreases mitochondrial oxidative phosphorylation and protects from obesity and diabetes. Cell 131:476-91.

40. Furukawa S, et al. (2004) Increased oxidative stress in obesity and its impact on metabolic syndrome. J. Clin. Invest. 114:1752-61.

41. Ramana KV, Fadl AA, Tammali R, Reddy AB, Chopra AK, Srivastava SK. (2006) Aldose reductase mediates the lipopolysaccharide-induced release of inflammatory mediators in RAW264.7 murine macrophages. J. Biol. Chem. 281:33019-29.

42. Janssens S, Tschopp J. (2006) Signals from within: the DNA-damage-induced NF-kappaB response. Cell Death Differ. 13:773-84.

43. Pacheco ME, Beltran A, Redondo J, Manso AM, Alonso MJ, Salaices M. (2006) High glucose enhances inducible nitric oxide synthase expression: role of protein kinase C-betaII. Eur. J. Pharmacol. 538:115-23.

44. Carreras MC, Poderoso JJ. (2007) Mitochondrial nitric oxide in the signaling of cell integrated responses. Am. J. Physiol. Cell Physiol. 292:C1569-80.

45. Du XL, Edelstein D, Dimmeler S, Ju Q, Sui C, Brownlee M. (2001) Hyperglycemia inhibits en- 
dothelial nitric oxide synthase activity by posttranslational modification at the Akt site. J. Clin. Invest. 108:1341-8.

46. Kwon NS, Nathan CF, Stuehr DJ. (1989) Reduced biopterin as a cofactor in the generation of nitrogen oxides by murine macrophages. J. Biol. Chem. 264:20496-501.

47. Xu J, Wu Y, Song P, Zhang M, Wang S, Zou MH. (2007) Proteasome-dependent degradation of guanosine 5 '-triphosphate cyclohydrolase I causes tetrahydrobiopterin deficiency in diabetes mellitus. Circulation 116:944-53.

48. Upmacis RK, et al. (2007) Profound biopterin oxidation and protein tyrosine nitration in tissues of ApoE-null mice on an atherogenic diet: contribution of inducible nitric oxide synthase. Am. J. Physiol. Heart Circ. Physiol. 293:H2878-87.

49. Yin L, et al. (2007) Rev-erbalpha, a heme sensor that coordinates metabolic and circadian pathways. Science 318:1786-9.

50. Odegaard JI, et al. (2007) Macrophage-specific PPARgamma controls alternative activation and improves insulin resistance. Nature 447:1116-20.

51. Schopfer FJ, et al. (2005) Nitrolinoleic acid: an endogenous peroxisome proliferator-activated receptor gamma ligand. Proc. Natl. Acad. Sci. U. S. A. 102:2340-5.

52. Pascual G, et al. (2005) A SUMOylation-dependent pathway mediates transrepression of inflammatory response genes by PPAR-gamma. Nature 437:759-63.

53. Hosogai N, et al. (2007) Adipose tissue hypoxia in obesity and its impact on adipocytokine dysregulation. Diabetes 56:901-11.

54. Ye J, Gao Z, Yin J, He Q. (2007) Hypoxia is a potential risk factor for chronic inflammation and adiponectin reduction in adipose tissue of $o b / o b$ and dietary obese mice. Am. J. Physiol. Endocrinol. Metab. 293:E1118-28.

55. Guzy RD, et al. (2005) Mitochondrial complex III is required for hypoxia-induced ROS production and cellular oxygen sensing. Cell Metab. 1:401-8.

56. Chen R, Yang L, McIntyre TM. (2007) Cytotoxic phospholipid oxidation products. Cell death from mitochondrial damage and the intrinsic caspase cascade. J. Biol. Chem. 282:24842-50.

57. Cinti S, et al. (2005) Adipocyte death defines macrophage localization and function in adipose tissue of obese mice and humans. J. Lipid Res. 46:2347-55.

58. Kanda H, et al. (2006) MCP-1 contributes to macrophage infiltration into adipose tissue, insulin resistance, and hepatic steatosis in obesity. J. Clin. Invest. 116:1494-505.

59. Alisjahbana B, et al. (2007) The effect of type 2 diabetes mellitus on the presentation and treatment response of pulmonary tuberculosis. Clin. Infect. Dis. 45:428-35.

60. Restrepo BI. (2007) Convergence of the tuberculosis and diabetes epidemics: renewal of old acquaintances. Clin. Infect. Dis. 45:436-8.

61. Stevenson CR, et al. (2007) Diabetes and tuberculosis: the impact of the diabetes epidemic on tuberculosis incidence. BMC Public Health 7:234.
62. Stalenhoef JE, et al. (2007) The role of interferongamma in the increased tuberculosis risk in type 2 diabetes mellitus. Eur. J. Clin. Microbiol. Infect. Dis. 27:97-103.

63. Nathan CF, Murray HW, Wiebe ME, Rubin BY. (1983) Identification of interferon-gamma as the lymphokine that activates human macrophage oxidative metabolism and antimicrobial activity. J. Exp. Med. 158:670-89.

64. Fortin A, Abel L, Casanova JL, Gros P. (2007) Host genetics of mycobacterial diseases in mice and men: forward genetic studies of BCG-osis and tuberculosis. Annu. Rev. Genomics Hum. Genet. 8:163-92.

65. Kensler TW, Wakabayashi N, Biswal S. (2007) Cell survival responses to environmental stresses via the Keap1-Nrf2-ARE pathway. Annu. Rev. Pharmacol. Toxicol. 47:89-116.

66. Yates MS, et al. (2007) Pharmacodynamic characterization of chemopreventive triterpenoids as exceptionally potent inducers of Nrf2-regulated genes. Mol. Cancer Ther. 6:154-62.

67. House of Lords, Select Committee on Science and Technology. c1998. Science and Technology Seventh Report [Internet]. House of Lords; [cited 2008 Feb 23]. Available from: http:/ / www. parliament.the-stationery-office.co.uk/pa/ 1d199798/1dselect/ldsctech/081vii/st0701.htm.

68. Consumer concerns about hormones in food: fact sheet \#37 [Internet]. c2008. Ithaca, NY: Program on Breast Cancer and Environmental Risk Factors, Cornell University, College of Veterinary; [updated 2003 May 2; cited 2008 Feb 23]. Available from: http:/ /envirocancer.cornell.edu/ Factsheet/Diet/fs37.hormones.cfm.

69. Donn J, Mendoza M, Pritchard J. March 9, 2008. AP: drugs show up in Americans' water. USA Today [Internet]. [updated 2008 Mar 11; cited 2008 Feb 23]. Available from: http:/ / www.usatoday. com/news/health/2008-03-09-water_N.htm. 